\title{
Análisis de los rasgos lingüísticos de Maus y sus interferencias en la traducción al español
}

Art Spiegelman abrió con Maus (1980-1991) un nuevo camino para la novela gráfica a nivel internacional: entrevistando a su padre, que le cuenta sus memorias sobre el Holocausto, presenta una historia de carácter confesional, inédita hasta entonces en este ámbito de manifestación artísticoliteraria. Junto con la impactante representación de los personajes, destaca especialmente la historia de supervivencia en primera persona. En este trabajo, analizamos la importancia del lenguaje en Maus, y más concretamente los rasgos lingüísticos que caracterizan la forma de expresión del protagonista, cuya lengua materna no era el inglés, sino el polaco. Son numerosas las incoherencias y errores intencionados en el original (por ejemplo, “... I can tell you other stories, but such private things, I don't want you should mention"). Para ello, trataremos de determinar si existen en estas incoherencias parámetros recurrentes y posibles influencias de otra(s) lengua(s). Finalmente, analizaremos cómo han podido interferir estas pautas en la traducción al español de una de las novelas gráficas más destacadas del siglo XX y la primera ganadora del Premio Pulitzer en 1992. 